\title{
ТОВАРООБМЕННАЯ ТРАНСФОРМАЦИЯ ТРУДОВЫХ ОТНОШЕНИЙ В РАМКАХ ТРАДИЦИОННОГО ТРУДОВОГО ДОГОВОРА
}

\section{() 2021 Будович Юлия Ивановна}

доктор экономических наук, доцент, профессор Департамента экономической теории Финансовый университет при Правительстве Российской Федерации, Россия, Москва

E-mail: JBudovich@fa.ru

ORCID: https://orcid.org/0000-0001-8691-947X

В настоящей статье показано, что в мире уже давно идет процесс товарообменной трансформации труда, продаваемого по традиционным трудовым договорам, связанный с вовлечением рядовых работников в управление своим трудом. В качестве доказательства приводится отражение этого процесса в современных концепциях менеджмента персонала. Из того, что имеются примеры их массового внедрения в компаниях, а также их популярности, делается вывод, что развитие соответствующих концепций в науке «менеджмент» сопровождается углублением реальной товарообменной трансформации трудовых отношений в рамках традиционного трудового договора.

Ключевые слова: трудовой договор, договор гражданско-правового характера, трансфертный труд, товарообменный труд, теория $X$, теория $Y$, обучающаяся организация, ответственность за резульmam.

В опубликованной в данном номере журнала «Экономические науки» статье К.Н.Лебедева «Труд трансфертный и товарообменный» показано, что система обеспечения экономики фактором «труд», как и любая система ресурсообеспечения, состоит из альтернативных трансфертной и товарообменной подсистем, или из подсистем трансфертного и товарообменного труда. Для трансфертного труда характерна оплата, близкая к прожиточному минимуму, но при этом забота об эффективном использовании труда работника лежит на получателе труда, а для товарообменного - значительно более высокая оплата, соответствующая стоимости продукта труда, но при этом забота об эффективном использовании труда работника на благо работодателя лежит на самом работнике. Более высокая плата за товарообменный труд назначается не только за то, что работник сам управляет своим трудом и максимизирует его полезность для получателя труда, но и за то, что работник не требует от получателя труда никаких социальных гарантий (оплачиваемый отпуск, отчисления на обеспечение в старости, оплата простоя и т.д.). Юридическим отражением существования трансфертной и товарообменной альтернатив обеспечения трудом является существование двух альтернативных вариантов оформления трудовых отношений работника с организацией - по трудовому договору и по договору гражданско-правового характера (ГПХ). В вышеуказанной статье К.Н.Лебедева также отмечено, что товарообменные системы ресурсообеспечения являются более эффективными (более доступными, более экономичными и менее опасными), чем трансфертные с точки зрения как ресурсодателей, так и ресурсополучателей, в силу чего в мире происходит вытеснение трансфертных систем ресурсообеспечения (традиционных финансов) товарообменными (альтернативными финансами). И было показано, что и товарообменные системы обеспечения ресурсом «труд» являются более эффективными чем трансфертные аналоги, и с точки зрения как получателей труда (работодателей), так и работников.

Цель настоящей статьи - показать, что в современном мире реально идет процесс вытеснения трансфертного труда товарообменным, причем он уже давно идет скрыто в виде товарообменной трансформации трудовых отношений, оформляемых традиционным трудовым договором.

В другой работе К.Н.Лебедева из цикла статей, посвященных труду, опубликованной в настоящем номере журнала «Экономические науки», которая называется «Освобождение труда с точки зрения теории альтернативных финан- 
сов», была представлена реконструкция стадий процесса вытеснения, наоборот, трансфертным трудом товарообменного труда в отношениях вольного найма («закабаления труда»), с которого началось развитие капитализма, предшествовавшего происходящему в настоящее время обратному процессу вытеснения товарообменным вольнонаемным трудом трансфертного труда («освобождения труда»). Согласно этой реконструкции, окончательное закабаление труда было связано с лишением наемных работников такой функции управления своим трудом, как (самостоятельное) определение способа исполнения порученных им операций, в том числе с использованием машин (что стало задачей инженеров, готовящих теперь для рабочих подробные операционные инструкции, рабочие правила и т.д.), которое происходило в начале $\mathrm{XX}$ в. в форме внедрения на предприятиях научной организации труда (НОТ). Заметим, что это окончательное закабаление труда пришлось на такой период развития капитализма, как его превращение в империализм, т.е. загнивающий и паразитический капитализм, что, согласно марксистской теории, произошло на рубеже XIX и XX вв. [8, с. 364]. Очевидно, что исходное состояние промышленности до начала развития капитализма, которым является кустарное и ремесленное производство, должно было соответствовать трудовым отношениям в рамках договора ГПХ (подряда, возмездного оказания услуг и т.д.). При этом современная система социальных гарантий в трудовых отношениях между работодателями и работниками в основном сформировалась только к середине 1930-х гг., что было ускорено самым разрушительным в истории мировой экономики кризисом 1929-1933 г., а система социальных гарантий работникам является одним из отличительных признаков трудового договора. Освобождение же труда, согласно реконструкции К.Н.Лебедева, началось в СССР в 1935 г. с возврата к самостоятельной разработке рабочими исполняемых ими операций, прежде всего машинных, теперь уже только с помощью инженеров, ознаменовав начало стахановского движения, названного в честь донбасского шахтера Алексея Стаханова, перевыполнившего в 1935 г. в 14 раз норму по добыче угля. Отсюда следует, что трансфертная трансформация трудовых отношений (закабаление труда) при капитализме происходила в рамках традиционного договора ГПХ, который на последней стадии закабаления труда трансформировался в трудовой договор. Поэтому, применяя принцип инволюции (обратного развития), вполне обоснованно предположить, что и обратная товарообменная трансформация трудовых вольнонаемных отношений (освобождение труда) должна происходить, прежде всего, в рамках традиционного трудового договора.

Выше отмечалось, что трансфертная экономика через своих агентов, которым зачастую выступает государство, близкое к традиционным финансам, оказывает сопротивление развитию альтернативных товарообменных отношений. Не сложно обнаружить, что государство препятствует выходу трудовых отношений за рамки традиционного трудового договора, обременяющего получателей труда социальными гарантиями для работников, сдерживая тем самым процесс вытеснения трансфертного труда товарообменным (см. другую нашу статью в данном номере журнала). Это объясняется, очевидно, прежде всего, желанием государства оставить за получателями труда соответствующее бремя, очевидно, в качестве наказания, обосновываемое тем, что сам бизнес, прежде всего, виноват в индивидуальных, локальных и общих экономических кризисах, сокращающих его спрос на труд; тягой бизнеса к маскировке трансфертных трудовых отношений договорами ГПХ, позволяющими избавиться от бремени социальных гарантий; желанием государства переложить на плечи получателей труда заботу о контроле за уплатой налога с трудового дохода, и т.д. В условиях, когда государство фактически преследует бизнес и труд за оформление трудовых взаимоотношений договорами ГПХ, замещение трансфертных трудовых отношений товарообменными неизбежно и должно было происходить, прежде всего, в рамках традиционного трудового договора (в широком смысле не как соответствующего документа, а как всей совокупности соответствующих трудовых отношений, в том числе системы оплаты труда).

В данной статье мы приведем такое доказательство того, что в мире уже давно идет процесс замещения более эффективным товарообменным трудом трансфертного труда в рамках традиционного трудового договора, как отражение этого процесса в западных концепциях менеджмента персонала, т.е. управления штатными сотрудниками (сотрудниками, оформленными на работу по трудовым договорам). 
Следует отметить, что данное исследование является ярким примером использования принципа несоответствия реальных производственных отношений их юридической форме (в данном случае - трудовых отношений их юридической форме), которая зачастую не только просто искажает эти реальные отношения, но и сдерживает их прогрессивное развитие. Следует отметить, что юридическая форма является и существенным фактором себестоимости трудового дохода (для работника) и трудового результата (для получателя труда). Так, трансфертное по форме (т.е. на основе трудовых договоров) получение труда предприятием предполагает содержание им кадровой службы, бухгалтерии в части, связанной с учетом оплаты труда.

Общепризнанно, что развитие трудовых отношений со штатными сотрудниками приобрело научный характер с выходом трудов Ф. У. Тейлора, одного из лидеров движения за внедрение HOT, и идет по пути повышения заинтересованности работников в конечных результатах их труда (с точки зрения их количества, качества, затрат материалов и т.д.), что предполагает установление тесной связи между этими результатами и вознаграждением за труд [3]. Очевидно, что результативность труда работника при этом может быть увеличена двумя способами: 1) путем повышения качества управления трудом работника со стороны работодателя и 2) путем передачи работнику обязанностей по управлению передаваемым им работодателю трудом, нацеленному на максимизацию полезности его конечного результата для работодателя. При этом первоначально научное (т.е. на основе рекомендаций науки) развитие отношений со штатными сотрудниками пошло по пути обеспечения работника работодателем эффективными операционными инструкциями, рабочими правилами и указаниями и материального стимулирования их строгого исполнения, что и стало называться внедрением НОT. Результатом внедрения на предприятиях НОТ, как уже отмечалось выше, стало, наоборот, (окончательное) вытеснение элементов товарообменного труда из вольнонаемного труда, так как до этого рабочие сами определяли способ исполнения порученных им операций, в связи с чем круг их обязанностей по управлению собственным трудом был шире, чем до введения НОТ. Однако затем научное развитие отношений со штатными сотрудниками пошло, наоборот, по пути передачи работнику обя- занностей по управлению собственным трудом, нацеленному на максимизацию полезности его конечного результата для получателя труда, и материального стимулирования такого самоуправления труда.

Западные специалисты по менеджменту отмечают факт революции, произошедшей в развитых капиталистических странах в отношениях между менеджерами и работниками, состоящей в том, что к последним перестали относиться как к дополнениям, или придаткам, машин, разглядев в них живых людей, однако, на наш взгляд, они ошибочно связывают ее с использованием в управлении персоналом результатов хоторнских экспериментов, производившихся в 1924-1932 гг. психологом Элтоном Мэйо в компании Western Electric в г. Хоторн (Иллинойс, США). Эксперименты начались из-за того, что упала производительность труда сборщиц реле, и состояли в изучении влияния на производительность труда нормализации его условий (вначале освещения, затем перерывов в труде и т.д.). Эксперименты, естественно, показали, что улучшение условий труда ведет к росту производительности, но также и то, что рост производительности происходил и в контрольной группе, а отмена улучшений приводила лишь к незначительному спаду производительности труда. Это заставило Э. Мэйо предположить, что фактором производительности стало само участие работниц в эксперименте или их отклик на внимание руководства к нуждам работников, в связи с чем и возникло понятие «человеческие отношения» на производстве [10]. Однако рост производительности труда в данном случае не был связан с передачей работникам функций по управлению от работодателей, т.е. с товарообменной трансформацией вольнонаемного труда, а был результатом внедрения на производстве той же НОТ, которое просто показало, что после возврата условий труда к прежним ненормальным работники по инерции продолжают трудиться более производительно. Настоящей революцией в отношениях между менеджерами и рабочими был бы возврат работникам функций по управлению, соответствующий разным или одновременно нескольким стадиям освобождения труда, к которым К.Н.Лебедев относит возврат работникам функций по разработке осуществляемых ими операций, переход работников от управления отдельными операциями к управлению всем производственным процессом, возвраще- 
ние работникам права самостоятельно распределять свой труд во времени и возвращение им функций по управлению сбытом и реализации изготавливаемых ими продуктов. Преобразования же в управлении персоналом, соответствующие внедрению на предприятиях человеческих отношений, подобных преобразований в менеджменте персонала не отражают. Соответственно, они не отражают и товарообменной трансформации труда штатных сотрудников компаний.

Это видно из описания соответствующих преобразований, которые приводит западный специалист по менеджменту Р.Дафт в своей книге «Менеджмент» (2006). Одним из первых случаев введения на предприятиях человеческого отношения к рабочим выступают преобразования производственной системы International Business Machines (IBM), осуществленные Т.Уотсоном-старшим, основателем и управляющим IBM, который, вопреки концепции управления персоналом Ф.У.Тейлора, отменил сдельную оплату труда, повысил оклады, ввел обучающие программы, гарантировал работникам пожизненную занятость, внедрил политику «открытых дверей», когда работник имел возможность высказывать пожелания и замечания непосредственно Т.Уотсону-старшему, стал устраивать за счет компании пикники для поддержания рабочего настроя, ввел (очевидно, одним из первых) в 1934 г. всеобщее страхование жизни, а затем - пособия в связи с утратой кормильца и оплачиваемые отпуска. Именно с продолжением политики человеческих отношений связывают бурный период роста IBM после того, как в 1956 г. отца на посту исполнительного директора сменил Т. Уотсон-младший, прославивший компанию еще и тем, что все ее сотрудники получали фиксированную зарплату, но имели многочисленные льготы и привилегии, в том числе сохраненную гарантию пожизненного найма [1, с. 83]. Не сложно обнаружить, что все приведенные выше преобразования выступают всего лишь развитием материального стимулирования заинтересованности работников в конечных результатах труда в виде стимулирования их стремления тщательно исполнять спущенные сверку операционные инструкции, рабочие правила, должностные обязанности и указания с целью окончательного закрепощения труда. Таким образом, движение за внедрение человеческих отношений не означало замещения трансфертного труда товарообменным.
Неслучайно Дуглас Макгрегор, концепция управления персоналом которого действительно отражает товарообменную трансформацию труда персонала, как сообщает Р.Дафт, охарактеризовал движение за человеческое отношение всего лишь как модифицированный вариант отношения к людям как к придаткам машин [1, с. 85]. Д. Макгрегор выступил автором концепций двух типов представления менеджеров о работниках, вызывающих соответствующее отношение первых к последним, представленные в его книге «Человеческая сторона предпринимательства» (1960). Концепция первого типа представления о работниках (теория X) исходит из того, что средний работник испытывает отвращение к труду и стремится отлынивать от работы при малейшей возможности, в связи с чем для достижения целей организации работника следует принуждать к труду, направлять и контролировать, угрожая наказанием за неисполнение, что средний работник предпочитает получать приказы, избегать ответственности, нечестолюбив и больше всего ценит безопасность [5, с. 187-188]. Концепция второго типа представления о работниках (теория Ү) исходит из того, что физическая и умственная деятельность свойственна среднему человеку подобно игре или отдыху, контроль извне и страх наказания не является единственным способом направления работника к достижению целей организации, преданность работника этим целям может обеспечить самоудовлетворение, являющееся результатом усилий, направленных на решение задач организации, средний работник, имеющий необходимую подготовку, не только может взять на себя ответственность, но и стремится к этому, людям присуща высокая степень сообразительности, воображения и творческой активности при достижении целей организации [5, с. 188]. По мнению Д. Макгрегора, сегодняшние (на конец 1950-х гг.- примеч. авт.) взгляды на человеческую сторону предпринимательства продиктованы теорией $\mathrm{X}$, однако современным организациям следует исходить из теории Ү, в связи с чем организациям нужно высвободить и направить энергию сотрудников на достижение организационных целей [5, с. 188].

О том, что теория Ү Д. Макгрегора отражает товарообменную трансформацию труда, передаваемого по традиционным трудовым договорам, говорит то, что характеристика теории X соответствует определению трансфертного тру- 
да, а характеристика теории Y - определению товарообменного вольнонаемного труда, т.е. внедрение теории Ү означает внедрение в компаниях товарообменного труда.

Значительно больше признаков товарообменного труда в теории Ү можно обнаружить в описаниях преобразований в организациях, осуществленных на основе теории Ү.Р.Дафт в своей книге в качестве примера внедрения теории Y приводит реорганизацию клининговой компании SOL Cleaning Services, в которой теперь нет названий должностей, распределения мест на парковке и других символов статуса, так что все сотрудники равны, все функции осуществляют самоуправляемые команды, сами определяющие свой бюджет, нанимающие нужных работников, выстраивающие отношения с клиентами, внедрены программы обучения (бюджетированию, управлению временем, обслуживанию клиентов и т.д.), уборщики и уборщицы фактически превращены в предпринимателей [1, с. 85]. Так, отсутствие названий должностей и других признаков статуса соответствует трудовым отношениям, оформляемым договорами ГПХ, деятельность самоуправляемых команд соответствует деятельности производственных кооперативов (ПК), трудящиеся члены которых не заключают с ПК трудовых договоров, их занятость трактуется юридической наукой как форма самозанятости [7], а сами они считаются кустарями, только кооперированными, наконец, трактовка уборщиков и уборщиц как предпринимателей соответствует их статусу как индивидуальных предпринимателей (ИП) или самозанятых, работающих с нанимателями по договорам ГПХ.

Примеры внедрения теории Ү, как и то, что у нее было много последователей, далее, популярность книги Д. Макгрегора, пик которой пришелся на 1965 г., когда было продано 30 тыс. ее экземпляров, что было по тем временам беспрецедентной цифрой [5, с. 187], говорят о том, что благодаря теории Y на Западе действительно происходила товарообменная трансформация труда в рамках традиционного трудового договора. Известно, что сам Д. Макгрегор еще в начале 1950-х гг. помогал компании Proctor \& Gamble реорганизовать работу завода в Джорджии на базе модели, предусматривающей самоуправляемые команды, созданной на основе теории Ү, и эта модель вскоре была распространена на другие заводы компании [5, с. 190].

Интересно, что происхождение всего рево- люционного в западном менеджменте настолько сильно связалось с внедрением в организациях человеческих отношений, что все последующие концепции менеджмента персонала стали трактоваться как развитие концепции человеческих отношений. Так, современный историк менеджмента С. Крейнер даже Д. Макгрегора рассматривает как приверженца теории человеческих отношений [5, с. 190], Р.Дафт пишет, что современный менеджмент основан на использовании концепций менеджмента, являющихся развитием принципов гуманистического менеджмента $[1$, с. 88], к которым относится, например, концепция обучающейся организации.

Как пишет Р.Дафт, концепция обучающейся организации возникла и стала развиваться после выхода книги Питера Сенге «Пятая дисциплина: искусство и практика обучающихся организаций» (1990), в которой описываются организационные изменения, позволяющие компаниям адаптироваться во все более хаотичном современном мире. Обучающаяся организация - та, все работники которой участвуют в выявлении проблем и ищут уникальные способы их решения, цель организации - решение проблем (а не повышение эффективности, что является целью традиционной организации) [1, с. 92]. Сущностью ее считается наделение властью, или делегирование полномочий. Сама организация состоит из самоуправляемых команд (самостоятельно занимающихся календарным планированием, выбором методов работы и систем оплаты труда, обучением, координацией деятельности с другими командами). Наделение властью трактуется как раскрытие творческого потенциала и возможностей работников, для чего им предоставляется свобода (в традиционном менеджменте осуществляется, наоборот, ограничение свобод трудящихся), ресурсы, обучение и информация, необходимые для принятия решений и эффективного труда, что позволяет работникам выполнять рабочие задания без пристального контроля со стороны непосредственного руководства [1, с. 93]. Как пишет Р.Дафт, соответствующие преобразования в условиях появления новых информационных технологий обеспечили процветание существующей уже 100 лет фирме Cementos Mexicanos (Cemex) в современной нестабильной среде, сутью которых стало фактическое превращение каждого цементовоза фирмы в самостоятельную бизнес-единицу, возглавляемую человеком, 
мыслящим как бизнесмен, в связи с чем «окно доставки» сократилось с 3 часов до 20 минут и еще сократится вдвое [1, с. 98]. Как мы видим, в этом описании много признаков товарообменного труда, например уже рассматривавшиеся выше как таковые функционирование самоуправляемых команд и исполнение работниками (водителями цементовозов) роли бизнесмена, видно, что работникам предоставляются ресурсы, обучение и информация для эффективного труда, из чего можно заключить, что им передаются и функции по разработке своих трудовых процессов, что является признаком очередной товарообменной революции в труде, продающемся по трудовому договору.

Примеры внедрения концепции обучающейся организации, ее популярность также говорят о том, что соответствующая концепция менеджмента персонала, отражающая товарообменную трансформацию традиционного труда, привела к углублению этой трансформации в реальной трудовой жизни.

В настоящее время, по крайне мере в нашей стране, весьма популярной концепцией менеджмента является концепции ответственности сотрудников за результат. Об этом говорит обилие научных и практических исследований, посвященных проблеме повышения ответственности работников за конечные результаты их труда. Это, например, материал «Как повысить ответственность сотрудников за результат», который, помимо введения необходимого функционала (дайте возможность людям совершать ошибки, ставьте амбициозные, но реалистичные цели, ясно определите образ конечного результата для сотрудника, вовлекайте его в постановку целей и разработку планов и т.д.), обосновывает и необходимость вознаграждения за достижение результатов. При этом в нем отмечается, что ответственность сотрудников при выполнении своих задач является критически важным аспектом работы любой компании, от которого зависит не только индивидуальный профессиональный рост, но и общий результат [6]. О популярности вышеуказанной концепции менеджмента также говорит обилие экономической литературы, посвященной уровням самостоятельности работников, например материал «Удаленка: пять уровней самостоятельности сотрудников», согласно которому сотрудники условно делятся на тех, кто ждет прямых указаний; спрашивают, что нужно сделать; предлагают начальству свой план действий и затем его реализовывают; действуют самостоятельно, спрашивая у начальства совет по надобности; действуют полностью самостоятельно, отчитываясь перед начальством по окончании проекта [2]. Очевидно, что последний тип самостоятельности фактически означает продажу работником получателю труда конечного продукта этого труда, т.е. вплотную приближается к товарообменному труду.

Если исходить из того, что качество управления в организациях по мере развития науки «менеджмент» повышается, а одним из направлений повышения его качества является увеличение вовлеченности штатных работников в управление собственным трудом, нацеленное на обеспечение его конечных результатов, интересующих получателей труда, сопровождающееся соответствующим повышением оплаты труда, то можно утверждать, что в мире уже давно наблюдается процесс постепенной товарообменной трансформации трудовых отношений в рамках трудового договора, что и является отражением общей тенденции замещения товарообменным трудом трансфертного труда, происходящего в мире. При этом принцип несоответствия реальных производственных отношений, в данном случае - трудовых, их юридической форме, а также противодействие государства оформлению трудовых отношений договорами ГПХ, заставляет предположить, что во многих случаях за традиционными трудовыми договорами скрываются почти полноценные трудовые отношения ГПХ. Следует отметить, что эта, очевидно, масштабная часть общего процесса товарообменной трансформации вольнонаемного труда, к сожалению, скрыта от статистического наблюдения, так как ему в необходимом разрезе не подвергается деятельность по управлению, осуществляемая рядовыми штатными работниками компаний. Именно поэтому подтверждение процесса углубления товарообменной трансформации труда, продаваемого по трудовым договорам, носило выше логический характер.

При этом существует, по крайней мере, один тип труда, продаваемого по традиционным трудовым договорам и подвергшегося существенному товарообменному разложению, который легко поддается наблюдению. Это удаленный труд (удаленка, дистант, телетруд). Само появление удаленного труда, требующего для своего введения достижения штатными сотрудниками определенного уровня самоуправления, да 
и только установление самой его возможности, говорит о значительном пути, который прошла товарообменная трансформация труда сотрудников, работающих по трудовым договорам. Без достижения штатными сотрудникам необходимого для дистанта уровня склонности к самоуправлению для достижения целей организации, очевидно, их эффективный (т.е. без потери эффективности бизнеса) перевод на дистант не мог бы состояться. Как отмечают эксперты по удаленке, удаленный труд, как правило, требует от работников большей самостоятельности и ответственности, чем такая же работа в офисе [2]. По нашему мнению, наличие высокого уровня склонности к самоуправлению в интересах работодателя и обнаружил у штатных работников в 1972 г. Джек Ниллес, ученый Южнокалифорнийского университета, предложивший новый способ организации их труда - телеработу (работу на дому со связью с офисом по телефону), когда установил, что сотрудники вполне могут исполнять свои обязанности и дома [4]. Появление концепции телеработы, которую также можно в угоду традиции связать с развитием человеческого отношения к сотрудникам, требующей совершения очередного витка товарообменной трансформации труда по трудовому договору, таким образом, является еще одним подтверждением соответствующей трансформации трансфертного труда, происходящей в реальной жизни. При этом, учитывая отмеченное в начале абзаца, можно найти и данные, непосредственно отражающие масштабы соответствующей трансформации руда штатных сотрудников. Согласно опросу, проведенному в нашей стране службой исследований HeadHunter еще до пандемии коронавируса (с 25 декабря 2018 г. по 13 января 2019 г.), 69\% респондентов показали, что работают в офисе, 17\% являются штатными сотрудниками компаний на удаленке, а 14\% являются фрилансерами (очевидно, чистыми. - примеч. авт.) [9].

Перевод на удаленку не только становится возможным при наличии у работников существенной ответственности за результат, но и означает дальнейшее повышение такой ответственности (по причине неизбежного снижения возможностей по управлению их трудом со стороны работодателя при переводе работников на удаленку), в связи с чем выплата вознаграждений за труд при переводе штатных сотрудников на дистант должна иметь тенденцию к повышению. Но и без обнаружения такой тенденции в оплате труда ясно, что, переходя на удаленку, сотрудник снижает удельную себестоимость своего трудового дохода за счет экономии на перемещении из дома в офис и обратно, которая может быть огромной.

\section{Библиографический список}

1. Дафт Р. Менеджмент / Пер. с англ.-СПб.: Питер, 2006. 864 с.

2. Донских А. Удаленка: Пять уровней самостоятельности сотрудников / Яндекс Дзен. 25.04.2020. URL: https:// zen.yandex.ru/media/andreydonskih/udalenka-piat-urovnei-samostoiatelnosti-sotrudnikov-5ea3ece4156fe026d $33959 f 8$ (дата обращения: 26.10.2021).

3. Истоки возникновения понятия «оплата труда» / humantime. URL: http:/www.humantime.ru/publications/ istoki-vozniknoveniya-ponyatiya-\%c2\%aboplata-truda\%c2\%bb (дата обращения: 09.10.2021).

4. Как, когда и где появился фриланс / seoded.ru. URL: http://www.seoded.ru/istoriya/internet-history/freelance. html (дата обращения: 30.09.2021).

5. Крейнер С. Библиотека избранных трудов о бизнесе. Книги, сотворившие менеджмент / Пер с англ. - М.: Олимп-Бизнес, 2005. 368 с.

6. Меньшов Е. Как повысить ответственность сотрудников за результат / ADVANTA. URL: https://www.advantagroup.ru/blog/kak-povysit-otvetstvennost-sotrudnikov-za-rezultat/ (дата обращения: 09.10.2021).

7. Регистрация юридического лица / ЭЕ. Эксперт Лигал Эдвайс. Expert Legal Advice. URL: https://lallc.ru/ registraciya-yuridicheskih-lic-predprinimatelei/ (дата обращения: 14.08.2020).

8. Румянщев А.М., Козлов Г. А., Милейковский А. Г. и др. Политическая экономия: Учебник. Т. 1. Капиталистический способ производства.- М.: Политиздат, 1982. 558 с.

9. Сколько у нас фрилансеров и где они работают: результаты опроса / hh. 06.02.2019 // https://hh.ru/ article/24036 (дата обращения: 04.10.2021).

10. Хоторнский эксперимент / PsyLogik.ru. URL: https://psylogik.ru/232-hotornskij-jeksperiment.html (дата обращения: 20.10.2021). 